University of Nebraska - Lincoln

DigitalCommons@University of Nebraska - Lincoln

1988

\title{
Tephritid Olfaction: Morphology of the Antennae of Four Tropical Species of Economic Importance (Diptera: Tephritidae)
}

\author{
J. C. Dickens \\ u.s. Department of Agriculture, Agricultural Research Service \\ W. G. Hart \\ u.s. Department of Agriculture, Agricultural Research Service \\ D. M. Light \\ U. S. Department of Agriculture, Agricultural Research Service \\ E. B. Jang \\ U.S. Department of Agriculture, Agricultural Research Service, eric.jang@ars.usda.gov
}

Follow this and additional works at: https://digitalcommons.unl.edu/entomologyother

Part of the Entomology Commons

Dickens, J. C.; Hart, W. G.; Light, D. M.; and Jang, E. B., "Tephritid Olfaction: Morphology of the Antennae of Four Tropical Species of Economic Importance (Diptera: Tephritidae)" (1988). Entomology Papers from Other Sources. 94.

https://digitalcommons.unl.edu/entomologyother/94

This Article is brought to you for free and open access by the Entomology Collections, Miscellaneous at DigitalCommons@University of Nebraska - Lincoln. It has been accepted for inclusion in Entomology Papers from Other Sources by an authorized administrator of DigitalCommons@University of Nebraska - Lincoln. 


\title{
Tephritid Olfaction: Morphology of the Antennae of Four Tropical Species of Economic Importance (Diptera: Tephritidae) ${ }^{1}$
}

\author{
J. C. DICKENS, ${ }^{2}$ W. G. HART, ${ }^{3}$ D. M. LIGHT, ${ }^{4}$ AND E. B. JANG ${ }^{5}$ \\ U.S. Department of Agriculture, Agricultural Research Service
}

\begin{abstract}
Ann. Entomol. Soc. Am. 81(2): 325-331 (1988)
ABSTRACT Four types of sensilla are present on the antennal surface of four tropical tephritid species of economic importance-the Mexican fruit fly, Anastrepha ludens (Loew); the Mediterranean fruit fly, Ceratitis capitata (Wiedemann); the melon fly, Dacus cucurbitae Coquillett; and the oriental fruit fly, $D$. dorsalis Hendel. Three types of porous sensilla occur only on the funiculus. Two types of multiporous pitted sensilla (MPS) - thick-walled and thin-walled-house dendritic branches, and both are probably chemoreceptors. Electrophysiological recordings from cells associated with a thick-walled MPS in C. capitata showed that it responds to trimedlure, a known attractant. Multiporous grooved sensilla also occurring on the funiculus were, however, too small for recordings. No-pore sensilla are found only on the scape and pedicel, and electrophysiological recordings show them to be mechanoreceptors.
\end{abstract}

KEY WORDS Insecta, fruit flies, chemoreceptors, mechanoreceptors

THE IMPORTANCE of olfaction in the behavior of tephritids is well known (Prokopy et al. 1984, Sivinski \& Calkins 1986). Pheromones or other compounds have a major role in releasing various behaviors in several tephritid species. Previous research on olfactory responses of tephritid flies has concerned whole-organism, attractant responses to various compounds (Beroza \& Green 1963, Keiser et al. 1975). Only relatively recently has the behavior of certain fruit flies and its specific chemical (Fletcher 1977, Schoonhoven 1982) and visual cues, or both, been described (Prokopy \& Owens 1983). However, before a true understanding is gained of the mechanisms involved in tephritid behavior, basic knowledge of the structure and function of the receptors must be obtained.

Although the antennal sensilla of several species of Diptera have been investigated (Dethier et al. 1963, Slifer \& Sekhon 1964, Lewis 1971, Bay \& Pitts 1976, White \& Bay 1980, Hood Henderson \& Wellington 1982, Honda et al. 1983), information on olfactory receptors in tephritid flies is only recently available. Hallberg et al. (1984) described the structure of sensilla on the surface and within the single olfactory pit of the funiculus of the olive fly, Dacus oleae (Gmelin). Giannakakis \& Fletcher (1985) characterized the distribution and surface

\footnotetext{
${ }^{1}$ This article reports the results of research only. Mention of a proprietary product does not constitute an endorsement or a recommendation for its use by USDA.

${ }^{2}$ Boll Weevil Research Unit, Mississippi State, MS 39762

${ }^{3}$ Citrus Insects Research Laboratory, Weslaco, TX 78596.

4 Western Regional Research Center, Albany, CA 94710.

${ }_{5}$ Tropical Fruit and Vegetable Research Laboratory, Hilo, HI 96720.
}

structure of antennal sensilla on male and female Queensland fruit flies, D. tryoni (Froggatt).

Here we describe the antennae and associated sensilla of four tropical tephritid pests-the Mexican fruit fly, Anastrepha ludens (Loew); the Mediterranean fruit fly, Ceratitis capitata (Wiedemann); the melon fly, Dacus cucurbitae (Coquillett); and the oriental fruit fly, D. dorsalis (Hendel). We also demonstrate the function of several sensillar types by electrophysiological recordings from cells associated with them.

\section{Materials and Methods}

Insects. Anastrepha ludens emerged from pupae obtained from the USDA-APHIS rearing facility in Monterrey, Mexico. Because of quarantine regulations, adult Ceratitis capitata, Dacus cucurbitae, and Dacus dorsalis used for morphological studies performed in the continental U.S. were obtained in a fixative (Chauthani \& Callahan 1966) from the ARS-USDA Tropical Fruit and Vegetable Research Laboratory in Honolulu, Hawaii. For electrophysiological studies performed in Hilo, Haw., adult C. capitata were used from pupae at the Tropical Fruit and Vegetable Research Laboratory in Hilo.

Microscopy. Whole mounts used for light microscopy were prepared from antennae fixed for at least $24 \mathrm{~h}$ in a solution described by Chauthani \& Callahan (1966). Dehydration was in a graded series of ethanol and xylene. Mounting was in Canada balsam or Permount. Sections of antennae used for light microscopy were prepared as for transmission electron microscopy (TEM). Sections $2 \mu \mathrm{m}$ 
Table 1. Measurements $(\mu \mathrm{m})$ made from light micrographs of antennae of male and female $A$. ludens, $C$. capitata, D. cucurbitae, and D. dorsalis $(\vec{x} \pm \mathrm{SE} ; n=5)$

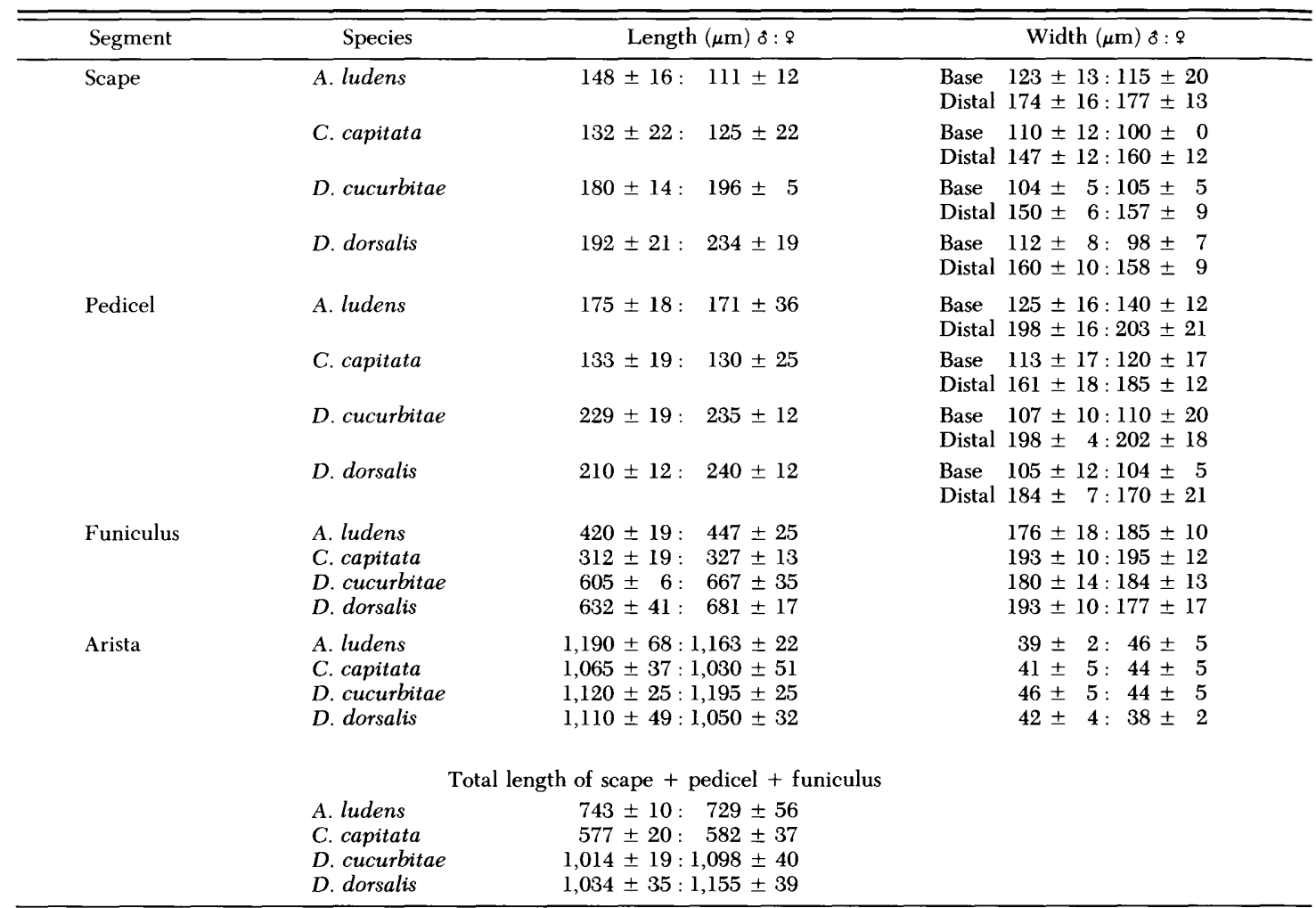

thick were stained with an aqueous $1 \%$ methylene blue/ $1 \%$ sodium borate solution. Both whole mounts and sections were examined using a Leitz Ortholux phase contrast microscope.

For scanning electron microscopy (SEM), either excised antennae or whole heads with antennae still attached were fixed several days in either a 5\% formalin solution or Chauthani \& Callahan's (1966) fixative prior to dehydration in a graded series of ethanol (Dickens \& Payne 1978). Specimens were then air-dried or critical point-dried and attached to aluminum stubs by conductive silver paint. Preparations coated with ca. $200 \AA$ of a $60: 40$ gold/ palladium mixture using a Hummer I were viewed on a JSM-35 scanning electron microscope at accelerating voltages of 20 to $30 \mathrm{kV}$.

For TEM studies, whole antennae or funiculi severed from adult A. ludens were immersed 2-8 $\mathrm{h}$ in a cold $3 \%$ glutaraldehyde fixative $(\mathrm{pH} 7.4)$ buffered with sodium cacodylate (Norton \& Vinson 1974). A slight vacuum was applied to remove air bubbles adhering to specimens during fixation. Following several cacodylate buffer washes, postfixation was in $2 \% \mathrm{OsO}_{4}$ for $2 \mathrm{~h}$. Dehydration was through a graded series of ethanol and propylene oxide. Embedding was in Spurr's (1969) medium. An LKB ultramicrotome and diamond knife were used to cut thin sections ca. $800 \AA$ thick, which were picked up on copper grids and stained with lead citrate (Sato 1967) and uranyl acetate. Sections on grids were viewed with either an Hitachi HU$11 \mathrm{E}$ or HS-8-2 TEM at an accelerating voltage of $50 \mathrm{kV}$. For orientation purposes, adjacent $1-2-\mu \mathrm{m}-$ thick sections were cut and examined by light microscopy.

Electrophysiology. Details of techniques are described elsewhere (Boeckh 1962, Dickens 1979, Dickens et al. 1984). In general, single-ended recordings were made using tungsten wire $0.125 \mathrm{~mm}$ in diameter electrolytically sharpened to a tip of approximately $1-2 \mu \mathrm{m}$. The recording electrode was positioned under optical control $(150 \times-200 \times)$ until contact was made with the funicular surface near the base of an apparent olfactory hair. Although one could discern individual cuticular structures on the funiculus at this magnification, it was not always possible to determine from which hair or even from which type of hair the recordings were made. However, this magnification was suitable for identification of individual sensilla on the scape and pedicel. The indifferent electrode, also a tungsten needle, was inserted into either the scape or head capsule. Recorded signals were amplified and conditioned by a Grass P-15 AC microelectrode preamplifier prior to display on a Tektronix 5113 analog storage oscilloscope. Records of electrical activity were made on polaroid film using a Tektronix C-5A oscilloscope camera. 


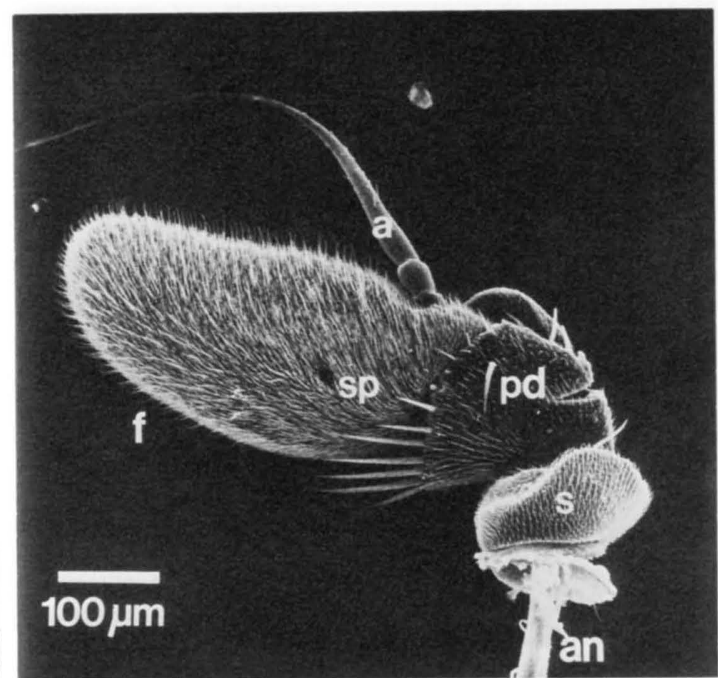

Fig. 1. SEM of antenna of C. capitata female showing shape and segments. a, arista; an, exposed antennal nerve; f, funiculus; pd, pedicel; s, scape; sp, sensory pit.

Trimedlure, a known attractant of the medfly, was used at $0.1 \mu \mathrm{g} / \mu \mathrm{l}$ as the olfactory stimulus. The stimulus compound diluted in hexane was delivered as a $10-\mu \mathrm{l}$ sample placed on filter paper. Stimulation methodology is discussed elsewhere (Dickens et al. 1984).

Statistical Methodology. Morphometric differences between the sexes of a species were tested for significance $(P<0.05)$ using a $t$ test for two means (Ostle 1963).

Voucher specimens have been deposited in the insect collection of the Department of Entomology, Mississippi State University, Mississippi State.

\section{Results}

Shape and Segments of the Antennae. Both sexes of all four species have the same shape and number

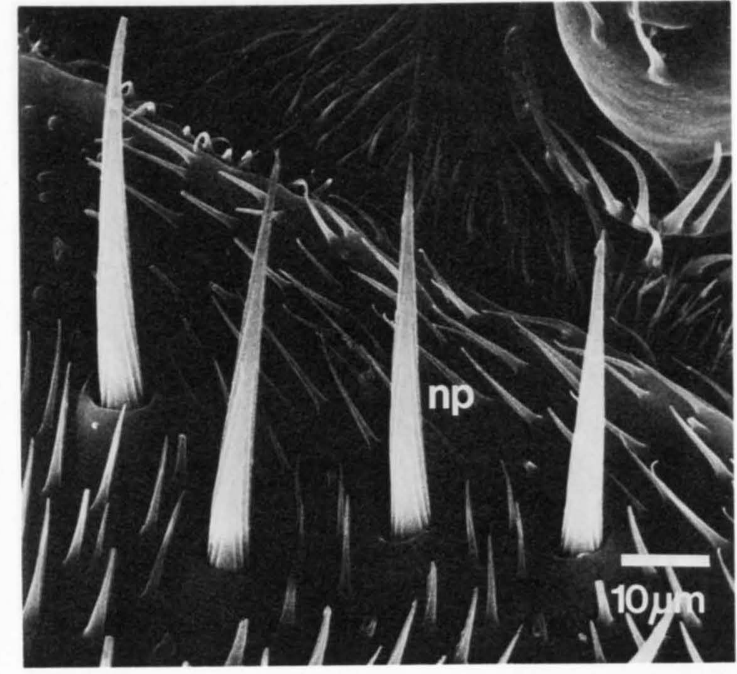

Fig. 2. SEM of NPS on pedicel of an A. ludens female. np, no-pore sensillum.

of antennal segments (Table 1). However, in both Dacus species, the combined scape, pedicel, and funiculus is longer in females than males $(P<$ 0.05 ).

The scape articulates with the antennal socket between the large compound eyes (Fig. 1). The pedicel is distally enlarged and dorsally evaginated and joins the greatly enlarged funiculus. From the dorsoproximal region of the funiculus arises an elongated trichoid arista, and a single sensory pit occurs on the medial side of the funiculus in each sex of all four species examined.

Distribution and Structure of Surface Antennal Sensilla. Antennal sensilla were grouped according to location, length, surface structure, and crosssectional morphology (Altner 1977, Zacharuk 1980). Except for the longitudinally ridged trichoid mechanosensory hairs along the distal margins of both

Table 2. Measurements $(\mu \mathrm{m})$ of sensilla on the antennae of A. ludens, $C$. capitata, D. cucurbitae, and $D$. dorsalis. Range derived from at least five measurements of each sensillar type for each sex and species

\begin{tabular}{|c|c|c|c|c|c|c|}
\hline & \multicolumn{2}{|c|}{ A. ludens $\delta: \uparrow$} & \multirow{2}{*}{$\frac{\text { C. capitata } \delta: ?}{\text { No-pore }}$} & D. cucurbitae oิ : $९$ & \multicolumn{2}{|c|}{ D. dorsalis $\delta: ?$} \\
\hline & & & & & & \\
\hline Length & $23-115.0$ & : $24-181$ & $13-95.0: 20.0-115$ & $38-80.0: 28.0-115$ & $43-132.0$ & : 31.0-117 \\
\hline Diameter base & $5.9-7.3$ & : $4.0-6.3$ & $3.3-6.0: 3.0-7.5$ & $4.2-5.6 \quad: 3.8-4.7$ & $2.5-7.5$ & : $3.0-7.0$ \\
\hline Diameter mid-height & $3.6-4.6$ & $: \quad 1.5-3.1$ & $1.7-4.5: 2.0-5.0$ & $2.8-4.2: 1.6-3.9$ & $2.0-5.0$ & $: \quad 2.0-5.0$ \\
\hline \multicolumn{7}{|c|}{ Thick-walled multiporous pitted sensilla } \\
\hline Length & $12.5-13.8$ & : 15.7-17.1 & $12.0-23.0: 17.3-23.3$ & $16.0-24.0: 18.0-22.0$ & $16.2-23.5$ & : 17.7-22.3 \\
\hline Diameter base & $1.6-2.3$ & $: \quad 2.0-2.5$ & $2.0-2.3: 2.0-2.3$ & $2.1-2.3: 2.0$ & $2.1-2.3$ & $: 2.0$ \\
\hline Diameter mid-height & $1.6-2.3$ & $: 1.2$ & $0.8-1.27: 1.0-1.2$ & $1.4-1.5: 1.3$ & $1.35-1.54$ & : 1.3 \\
\hline \multicolumn{7}{|c|}{ Thin-walled multiporous pitted sensilla } \\
\hline Length & $4.0-7.0$ & : $8.0-14.0$ & $6.0-11.0: \quad 6.0-11.0$ & $8.0-14.0: 8.0-13.0$ & $7.0-11.0$ & : $9.0-12.0$ \\
\hline Diameter base & $1.3-1.6$ & $: \quad 1.0-2.5$ & $1.3-1.5: 1.3-2.0$ & $1.4-1.7: 1.0-1.7$ & $1.3-2.0$ & $: 1.7-2.3$ \\
\hline Diameter mid-height & $0.9-1.3$ & : $0.8-1.3$ & $1.0-1.2: 0.7-1.3$ & $1.0-1.5: 1.0-1.2$ & $1.0-1.5$ & : $1.2-1.7$ \\
\hline \multicolumn{7}{|c|}{ Multiporous grooved sensilla } \\
\hline Length & $1.7-2.1$ & : $1.7-3.0$ & $1.4-2.5: 1.7-2.2$ & $2.3-3.1: 2.8-3.7$ & $2.3-3.3$ & : $1.5-2.0$ \\
\hline Diameter base & $0.8-1.2$ & : $0.8-1.0$ & $0.7-0.8: 0.7-0.8$ & $0.8-1.0: 0.8-1.0$ & $0.8-1.0$ & : 1.0 \\
\hline Diameter mid-height & $0.8-1.0$ & $: 0.7$ & $0.7-0.8: 0.7$ & $0.6 \quad: \quad 0.6-0.7$ & 0.7 & : $0.6-0.8$ \\
\hline
\end{tabular}



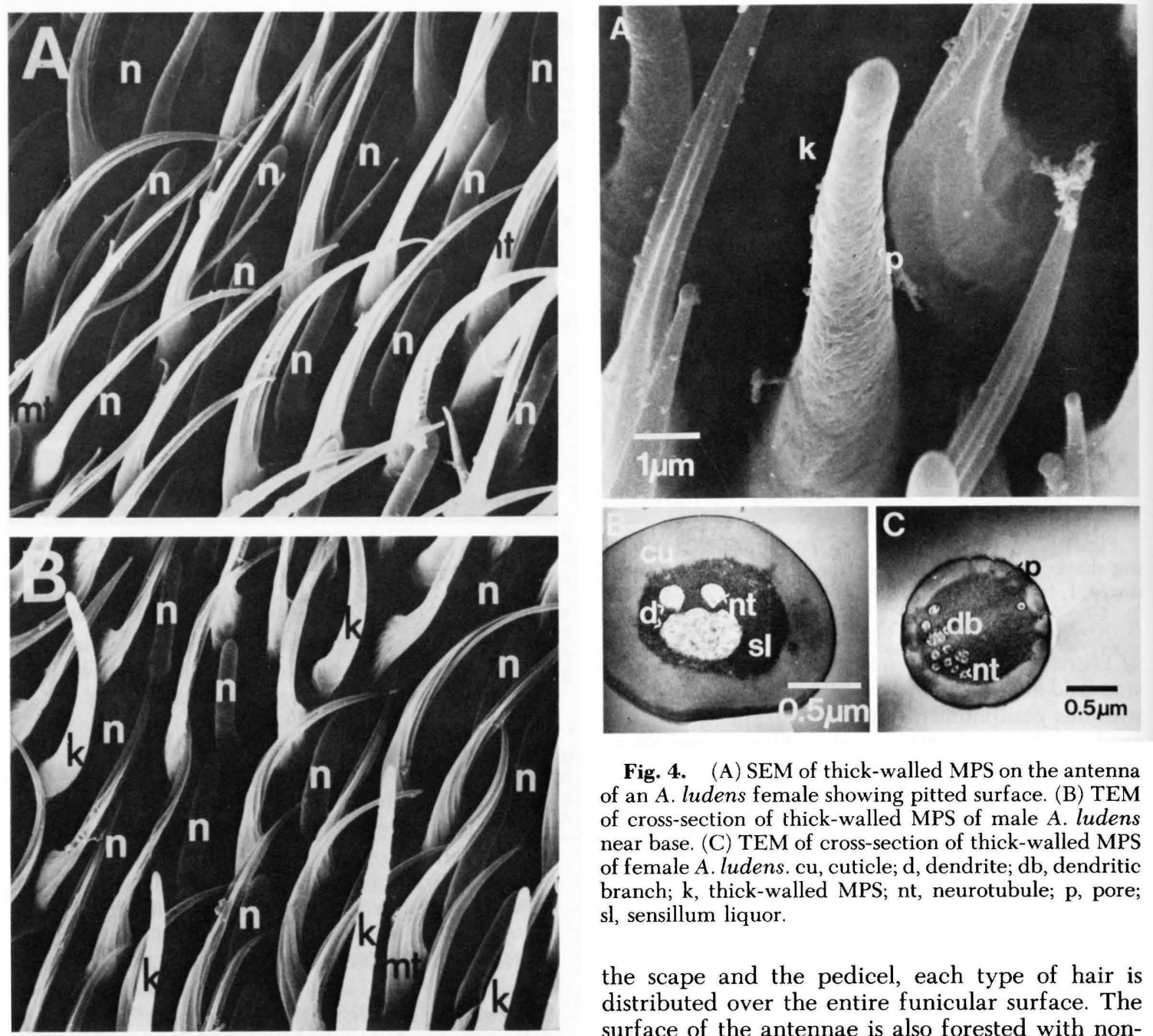

Fig. 4. (A) SEM of thick-walled MPS on the antenna of an A. ludens female showing pitted surface. (B) TEM of cross-section of thick-walled MPS of male A. ludens near base. (C) TEM of cross-section of thick-walled MPS of female A. ludens. cu, cuticle; d, dendrite; $\mathrm{db}$, dendritic branch; $k$, thick-walled MPS; nt, neurotubule; p, pore; sl, sensillum liquor.

the scape and the pedicel, each type of hair is distributed over the entire funicular surface. The surface of the antennae is also forested with noninnervated setae or microtrichia. These structures

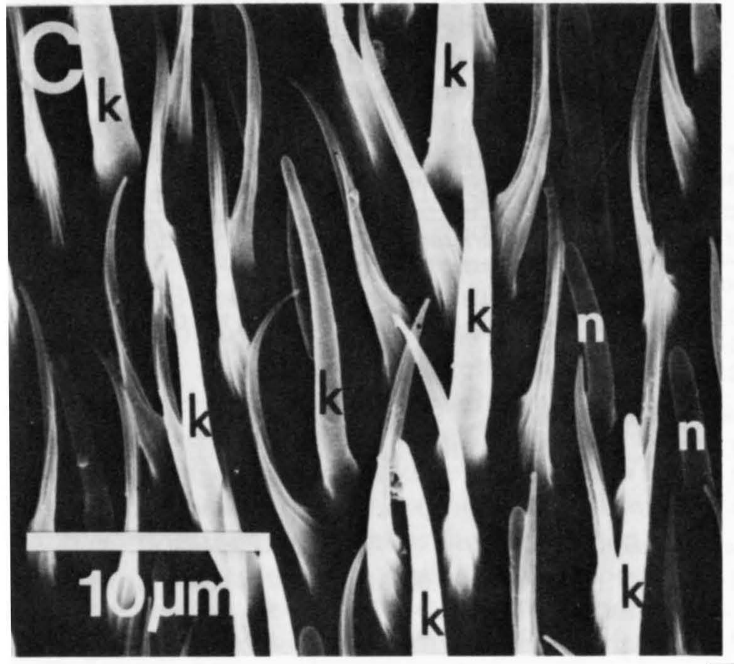
are curved, longitudinally ridged (for example, Fig.

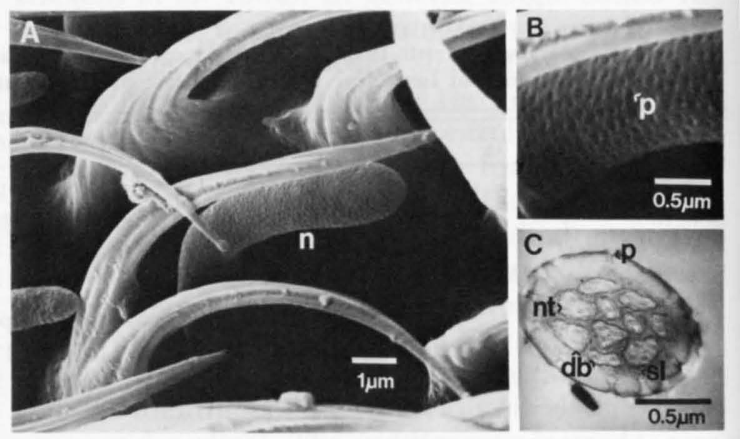

Fig. 5. (A) SEM of thin-walled MPS on the antenna of a $D$. dorsalis female showing pitted surface. (B) Higher magnification of surface of thin-walled MPS of a $D$. dorsalis female to magnify pore density. (C) TEM of cross-section of thin-walled MPS of an A. ludens male showing porous wall and dendritic branches within sensillum. db, dendritic branch; n, thin-walled MPS; nt, neurotubule; $p$, pore; sl, sensillum liquor.

Fig. 3. SEM of proximal (A), medial (B), and distal walled MPS; mt, microtrichia; $n$, thin-walled MPS. 


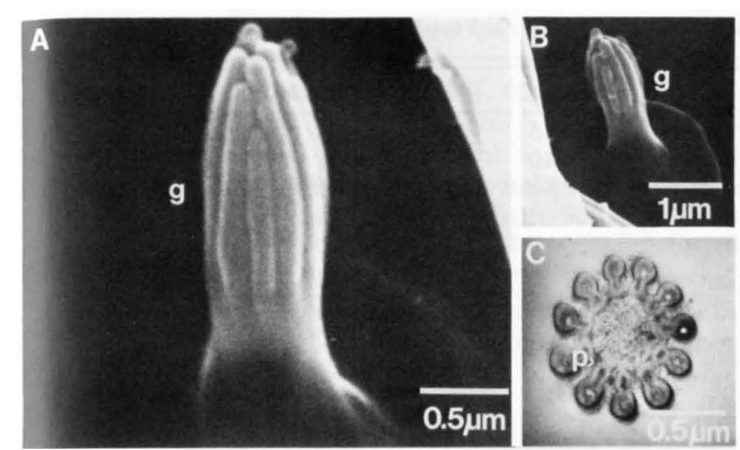

Fig. 6. (A) SEM of MPGS on the funiculus of a $C$. capitata female showing no apparent material associated with clefts. (B) Same, with substance apparently exuding from clefts. (C) TEM of a cross-section of a MPGS on the funiculus of an A. ludens female showing pores and digitiform nature of cuticular wall. $\mathrm{g}$, mpgs; $\mathrm{p}$, pore.

$3 \mathrm{~A}$ and $5 \mathrm{~A}$ ), and cross-sections show an electrondense center.

No-Pore Sensilla (NPS). The NPS, located distally on the scape and pedicel, are generally longer along the ventral margin of each of these segments (Fig. 2). These sensilla are distally pointed and longitudinally ridged, with socketed bases. They range in length from $13 \mu \mathrm{m}$ to $>180 \mu \mathrm{m}$ in the species examined and are the largest sensilla on the antenna (Table 2).

Thick-Walled Multiporous Pitted Sensilla (MPS). Thick-walled MPS are located over much of the funiculus but are more numerous on its distal and lateral portions (Fig. $3 \mathrm{~A}-\mathrm{C}$ ). These, the largest funicular sensilla, range from 12 to $24 \mu \mathrm{m}$ in length. These distally pointed sensilla have a nonsocketed base and a pitted surface (Fig. 4A). Proximally, the cuticular wall is nonporous and approximately 0.3 $\mu \mathrm{m}$ in diameter. Dendrites of two or three neurons and their associated neurotubules are present in the sensillum liquor within each sensillum (Fig.
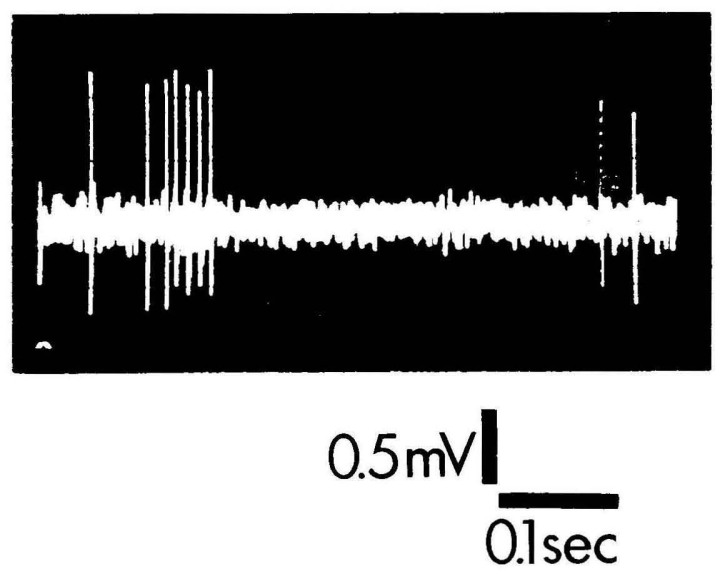

Fig. 7. Single-cell response of an NPS on the pedicel of a C. capitata male to mechanical stimulation. Arrow indicates onset of stimulus.

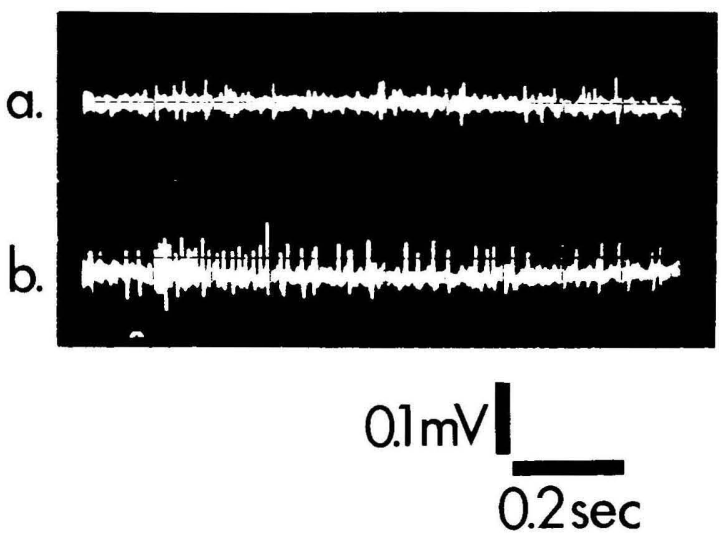

Fig. 8. Single cell response of two olfactory cells associated with a thick-walled MPS on the funiculus of a C. capitata male to volatiles emanating from hexane solvent and $1 \mu \mathrm{g}$ of trimedlure. Arrow indicates onset of stimulus.

$4 \mathrm{~B})$. In the distal region of the sensillum, dendritic branching occurs, and the cuticular wall is somewhat thinner (approximately $0.23 \mu \mathrm{m}$ ) and porous (Fig. 4C). Each dendritic branch has at least one neurotubule. Pores are 186-240 $\AA$ in diameter and lack pore kettles. In a C. capitata male, this sensillar type had a pore density of about 28 pores $/ \mu \mathrm{m}^{2}$.

Thin-Walled Multiporous Pitted Sensilla (MPS). Thin-walled MPS occur over the entire surface of the funiculus; however, they are most numerous in the proximal and ventral regions (Fig. $3 \mathrm{~A}-\mathrm{C})$. These sensilla are shorter than the thickwalled MPS and range in length from 4 to $14 \mu \mathrm{m}$ (Table 2). They have a nonsocketed base and are often curved proximally (Fig. 5A). Numerous pits on the surface (Fig. 5A and $5 \mathrm{~B}$ ) are shown in crosssection to be pores (Fig. 5C). The walls of this sensillar type were approximately $0.1 \mu \mathrm{m}$ thick and pore openings ranged from 503 to $670 \AA$ in an $A$. ludens male. In a $D$. dorsalis female, these sensilla had a pore density of 54-67 pores per $\mu \mathrm{m}^{2}$.

Multiporous Grooved Sensilla (MPGS). MPGS, the smallest sensilla on the funiculus, are 1.4-3.7 $\mu \mathrm{m}$ long (Table 2). These sensilla have a longitudinally grooved surface (Fig. $6 \mathrm{~A}$ and $\mathrm{B}$ ) which, in cross-section, can be seen to be composed of 11 digitiform processes (Fig. 6C). Although the digitiform processes of this sensillar type often appear "closed" (Fig. 6A), occasionally they appear open with a viscous substance associated with them (Fig. $6 \mathrm{~B})$. No definitive cell membranes could be identified in cross-sections of these sensilla (Fig. 6C).

Electrophysiology. Single-cell recordings were obtained from NPS on the scape and pedicel, and from thick-walled MPS on the funiculus of the medfly. Short volleys of spikes in response to mechanical stimulation of NPS indicated a mechanoreceptive function (Fig. 7A). Recordings made from cells associated with a thick-walled MPS on the funiculus of a medfly showed cells responsive to 
Table 3. Comparison of multiporous pitted sensilla on the funiculus of several tephritid species

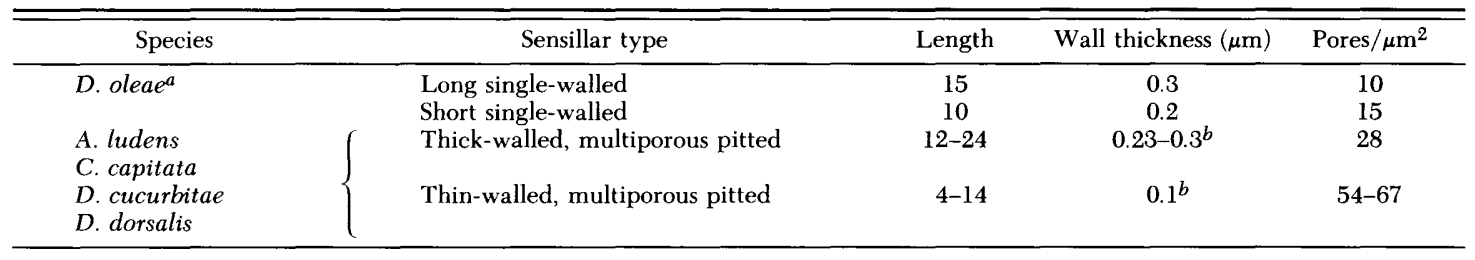

${ }^{a}$ Data from Hallberg et al. (1984).

${ }^{b}$ Measurements made only from transmission electron micrographs of A. ludens.

the volatile, trimedlure, a known attractant (Fig. $8 \mathrm{~A}$ and $\mathrm{B}$ ).

\section{Discussion}

Each of the tephritid species investigated had similar antennal morphology with regard to the number of segments, types of sensilla, and the presence of a single sensory pit. Although the size of the various sensillar types varied from species to species, their surface structure was consistent. The only significant conspecific morphometric difference was in the total length of the antennae of male and female Dacus species (Table 1). The density of cuticular structures on the funiculus made it impossible to count the number of funicular sensilla in scanning electron micrographs. However, the greater length of the female antenna might suggest females have more sensilla than males, as is true of the Queensland fruit fly, D. tryoni (Giannakakis \& Fletcher 1985).

The NPS described here are similar to mechanoreceptive sensilla described for other insect species (Altner 1977, Dickens \& Payne 1978, Zacharuk 1980). Both their socketed base and longitudinally ridged surface structure are characteristic of mechanoreceptive sensilla. Their location along the distal margins of the scape and pedicel, and the phasic nature of the response given by associated neuron(s), indicate their function in the orientation of the antenna.

Both thick- and thin-walled MPS have nonsocketed bases, multiporous pitted walls, and housed dendritic processes. Sensilla with similar structure function as olfactory receptors in several other insect species (Altner 1977, Zacharuk 1980). Hallberg et al. (1984) also described two types (based on surface structure and cross-sectional morphology) of MPS on the funiculus of the olive fly, D. oleae. However, a somewhat different situation was presented for the Queensland fruit fly, D. tryoni, by Giannakakis \& Fletcher (1985), who classified funicular hairs with multiple surface pits in four categories based on pit density and hair shape as discerned from scanning electron micrographs. The multiporous pitted sensilla of the species examined in the current study more closely resemble those of the olive fly (Table 3). Thick- and thin-walled MPS correspond both in length and wall thickness to the long and short single-walled sensilla in the olive fly. However, pore densities of the two sensillar types in the species we examined are greater than densities observed in the olive fly and more closely resemble those of the sensilla trichodia and sensilla basiconica II in the face fly, Musca autumnalis DeGeer (Bay \& Pitts 1976).

MPGS are similar to those in other insect species (Altner 1977, Zacharuk 1980), including D. oleae (Hallberg et al. 1984) and D. tryoni (Giannakakis \& Fletcher 1985). Sensilla with a similar grooved morphology in locusts (Boeckh 1967, Steinbrecht 1969, Waldow 1970) and a cockroach (Altner et al. 1977) house thermosensory, hygrosensory, or olfactory receptors.

\section{Acknowledgment}

The authors gratefully acknowledge critical reviews of the manuscript by T. L. Payne (Department of Entomology, Virginia Polytechnic Institute and State University, Blacksburg), Armand Whitehead (Department of Zoology, Brigham Young University, Logan, Utah), and W. L. McGovern, (U.S. Department of Agriculture, Agricultural Research Service, Crop Science Research Laboratory, Mississippi State, Miss.). J. C. Dickens is especially grateful for technical assistance provided by Randy Scott of the Electron Microscopy Center, Texas A\&M University, College Station.

\section{References Cited}

Altner, H. 1977. Insect sensillum specificity \& structure: an approach to a new typology. Olfaction Taste Proc. Int. Symp. 6: 295-303.

Altner, H., H. Sass \& I. Altner. 1977. Relationship between structure and function of antennal chemo-, hygro-, and thermoreceptive sensilla in Periplaneta americana. Cell Tissue Res. 176: 389-405.

Bay, D. E. \& C. W. Pitts. 1976. Antennal olfactory sensilla of the face fly, Musca autumnalis DeGeer (Diptera: Muscidae). Int. J. Insect Morphol. Embryol. 5: $1-16$.

Beroza, M. \& N. Green. 1963. Materials tested as insect attractants. U.S. Dep. Agric. Handb. 239.

Boeckh, J. 1962. Elektrophysiologische Untersuchungen an einzelnen Geruchs-Rezeptoren auf den Antennen des Totengrabers (Necrophorous, Coleoptera). Z. Vergl. Physiol. 46: 212-248.

1967. Reaktionsschwelle, Arbeitsbereich und Spezifität eines Geruchsrezeptors auf der Heuschreckenantenne. Z. Vergl. Physiol. 55: 378-406.

Chauthani, A. R. \& P. S. Callahan. 1966. A dissection technique for studying internal anatomy of different 
stadia of Noctuidae. Ann. Entomol. Soc. Am. 59: 10171018.

Dethier, V. G., J. R. Larsen \& J. R. Adams. 1963. The fine structure of the olfactory receptors of the blowfly. Olfaction Taste Proc. Int. Symp. 1: 105-114.

Dickens, J. C. 1979. Flectrophysiological investigations of olfaction in bark beetles. Mitt. Schweiz. Entomol. Ges. 52: 203-216.

Dickens, J. C. \& T. L. Payne. 1978. Structure and function of the sensilla on the antennal club of southern pine beetle, Dendroctonus frontalis (Zimmerman) (Coleoptera: Scolytidae). Int. J. Insect Morphol. Embryol. 7: 251-265.

Dickens, J. C., T. L. Payne, L. C. Ryker, \& J. A. Rudinsky. 1984. Single cell responses of the Douglasfir beetle, Dendroctonus pseudotsugae Hopkins (Coleoptra: Scolytidae), to pheromones and host odors. J. Chem. Ecol. 10:583-600.

Fletcher, B. S. 1977. Behavioral responses of Diptera to pheromones, allomones, and kairomones, pp. 129148. In H. H. Shorey and J. J. McKelvey, Jr. [eds.], Chemical control of insect behavior theory and application. Wiley, New York.

Giannakakis, A. \& B. S. Fletcher. 1985. Morphology and distribution of antennal sensilla of Dacus tryoni (Froggatt) (Diptera: Tephritidae). J. Aust. Entomol. Soc. 24 : $31-35$.

Hallberg, E., J. N. C. Van Der Pers \& G. E. Haniotakis. 1984. Funicular sensilla of Dacus oleae: fine structural characteristics. Entomol. Hellenica 2: 41-46.

Honda, I., Y. Ishikawa \& Y. Matsumoto. 1983. Morphological studies on the antennal sensilla of the onion fly, Hylemya antiqua Meigen (Diptera: Anthomyiidae). Appl. Entomol. Zool. 18: 170-181.

Hood Henderson, D. E. \& W. G. Wellington. 1982. Antennal sensilla of some aphidophagous Syrphidae (Diptera): fine structure and electroantennogramme study. Can. J. Zool. 60: 3172-3186.

Keiser, I., E. J. Harris \& D. M. Miyashita. 1975 Attraction of ethyl ether extracts of 232 botanicals to oriental fruit flies, melon flies, and Mediterranean fruit flies. Lloydia 38: 141-152.

Lewis, C. T. 1971. Superficial sense organs of the antennae of the fly Stomoxys calcitrans. J. Insect Physiol. 17: 449-461.

Vorton, W. N. \& S. B. Vinson. 1974. A comparative ultrastructural and behavioral study of the antennal sensory sensilla of the parasitoid Cardiochiles nigriceps (Hymenoptera: Braconidae). J. Morphol. 142: 329-350.

Ostle, B. 1963. Statistics in research. Iowa State University Press, Ames.

Prokopy, R. J. \& E. D. Owens. 1983. Visual detection of plants by herbivorous insects. Annu. Rev. Entomol. 28: $337-364$

Prokopy, R. J., B. D. Roitberg \& A. L. Averill. 1984. Resource partitioning, pp. 301-330. In W. J. Bell and R. T. Carde [eds.], Chemical ecology of insects. Sinauer Associates, Inc., Sunderland, Mass.

Sato, T. 1967. A modified method for lead staining of thin sections. J. Electron Microsc. 16: 133.

Schoonhoven, L. M. 1982. The role of chemoreception in hostplant finding and oviposition in phytophagous Diptera, pp. 240-247. In CEC/IOBC Symposium, Athens, November 1982

Sivinski, J. M. \& C. Calkins. 1986. Pheromones and parapheromones in the control of tephritids. Fla. Entomol. 69: 157-168.

Slifer, E. H. \& S. S. Sekhon. 1964. Fine structure of the sense organs on the antennal flagellum of a flesh fly, Sarcophaga argyrostoma R.-D. (Diptera, Sarcophagidae). J. Morphol. 114: 185-208.

Spurr, A. R. 1969. A low-viscosity epoxy resin embedding medium for electron microscopy. J. Ultrastruct. Res. 26: 31-43.

Steinbrecht, R. A. 1969. Comparative morphology of olfactory receptors. Olfaction Taste Proc. Int. Symp. 3: 3-21.

Waldow, U. 1970. Elektrophysiologische Untersuchungen an Feuchte-, Trocken- und Kalterezeptoren auf den Antenne der Wanderheuschrecke Locusta. Z. Vergl. Physiol. 69: 249-283.

White, S. L. \& D. E. Bay. 1980. Antennal olfactory sensilla of the horn fly, Haematobia irritans irritans (L.) (Diptera: Muscidae). J. Kans. Entomol. Soc. 53: 641-652.

Zacharuk, R. Y. 1980. Ultrastructure and function of insect chemosensilla. Annu. Rev. Entomol. 25: 2747.

Received for publication 1 April 1987; accepted 5 October 1987. 